\title{
France: too much analysis leads to paralysis?
}

Paris. French science faces a year of upheaval and confrontation in 1995, with the government seemingly intent on tackling the taboo of reforming both the university system and the country's largest research organization, the Centre National de la Recherche Scientifique (CNRS).

The moves are part of the government's plans for a new national strategy for research, based on the conclusions of a vast 'national consultation' on research that it organized last year (see Nature 369, 599; 1994). This urged France to "rediscover a strategic vision", and review methods for running research in the light of the economic and political changes of the past decade.

One argument is that the rapid growth in the scope of research possibilities means that choices must increasingly be made. This trend has been sharply reinforced by the freeze or reduction in research budgets imposed by the economic recession. Pressure is also mounting on scientists to justify spending and to provide better value for money.

Moreover, the general political trend towards greater liberalization and deregulation is leading France, like other countries, to review its policies for providing public aid to industry.

The government also claims that the public wants research to be more orientated towards social objectives, such as boosting economic competitiveness, reducing unemployment and improving the environment. The national 'strategy', it says, will allow research funds to be better matched to public policy needs, for example in health, transport, telecommunications, agriculture and energy. But the French debate is less about whether a strategy is needed than about redefining the respective roles of the government and research bodies.

Indeed, while the United Kingdom and other countries are for the first time seeking ways of planning research in the long-term, the French have been doing so for years.

Long-term policies in many sectors, including research, are regularly proposed, for example, by the powerful Commissariat général du Plan, a commission made up of industrialists, trade unions and representatives of various public organizations. Such forward planning has led, for example, to the creation of the grands programmes in space, nuclear science and aeronautics, and has provided successes such as the Ariane launchers and the Airbus airliners.

But such government dirigisme is now coming increasingly under fire. The national consultation concluded, for example, that the research system is "too rigid" and that the government intervenes in research too directly.

François Fillon, the French science min- ister, argues that the government should have a more hands-off approach and concentrate on "initiating, coordinating and stimulating".

At present, the French research system is bureaucratic. Most researchers are civil servants with life-time tenure, working for one of the research organizations, such as the

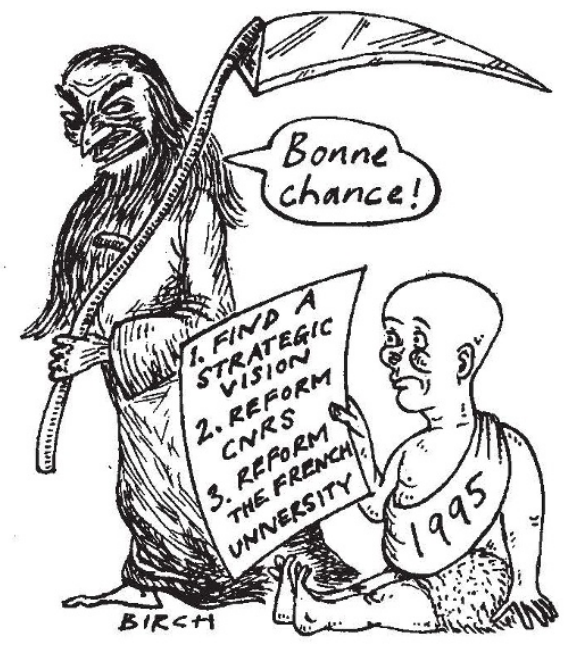

CNRS - - which employs 12,000 researchers and 15,000 support staff - or INSERM (see Nature 363, 751; 1994).

But the government has ruled out adopting the 'supplier-customer' model of research administration, which is favoured, for example, in the United Kingdom (see page 8 ). Observers argue that the model is flawed, because, although it assumes that the market can define research directions, it can do so only for short-term objectives. It cannot provide long-term strategy.

Indeed, some argue that 'foresight' exercises, which are currently fashionable in the United Kingdom and elsewhere, are a tacit acknowledgement that research policy cannot be driven by the market, in that their implicit aim is artificially to create demand and supply.

The emerging consensus in France is that the government's role should be to impose strict priorities for areas such as large equipment, technology transfer and applied and technological research, while leaving research organizations considerable freedom to choose which areas of basic research to support. Fillon says that to make long-term plans for basic research or innovation would be "illusory".

The structure proposed to articulate the government's strategy is a national committee for strategic orientation within the ministry of higher education and research. The committee - which will be made up of scientists, industrialists and representatives from other sectors, appointed by the prime minister - will also submit its recommendations to the National Assembly before the annual budget vote.

Fillon also plans to launch a system of five-year contracts with the research organizations, fixing objectives and the means to achieve them (see Nature 365, 196; 1993). Counterintuitively, this will probably result in less central control, not more. Contracts, says one observer, are a means by which the research organizations "negotiate" mediumterm objectives with the state in exchange for "liberty and autonomy".

One likely consequence is the transformation of the CNRS from a research organization employing thousands of researchers into a research council concerned primarily with distributing grants. At present, the agency allocates most of its research funds directly to its laboratories, but one proposal would shift much funding towards new 'programmes', where grants would be awarded on the basis of competitive proposals (see Nature 371, 639; 1994).

One problem is that the CNRS has little money to fund its proposed programmes because it spends more than three-quarters of its budget on salaries and overheads. To increase its margin for manoeuvre, the CNRS may reduce the number of its laboratories possibly from 1,300 laboratories to as few as 400 , with control of many passing to the universities. Such a move would be highly controversial.

In particular, although France has many first-class universities, the system is already hard pressed to recruit the staff needed to keep pace with burgeoning student numbers, and might not be able to afford to maintain new laboratories adequately.

Many argue that the universities need to be reformed if the CNRS is to be restructured successfully. That would be politically explosive. Successive left-wing governments have attempted to reform the university system, while keeping its nationalized status - the most recent with some success. But the right has regarded privatization as a remedy. Both have been impeded by the resistance to change of powerful lobbies of students and professeurs (see Nature 364, 5; 1993).

But the need to "reinvent" the French university is one of the main recommendations of a recent report, commissioned by Edouard Balladur, the prime minister, on the challenges facing France over the next decade. The report claims, in particular, that the universities lack leadership and policies, and that their systems of evaluation and management are "mediocre".

The report recommends that universities should be allowed to hire administrators from outside. It also asserts that "it is time to lift the taboo" on charging fees. "Free education is not providing equality", it argues, but "impoverishing" the universities.

Declan Butler 